\title{
Using Mixed Methods to Assess Social Capital \\ in Low Income Countries: A \\ Practical Guide
}

Veronica Nyhan Jones

World Bank

Michael Woolcock

University of Manchester

December 2007

vnyhan@worldbank.org

Michael.woolcock@manchester.ac.uk

BWPI Working Paper 12

Brooks World Poverty Institute

The University of Manchester

Humanities Bridgeford Street Building Oxford Road

Manchester, M13 9PL U.K. 


\begin{abstract}
We provide an overview of some practical guidelines for using both qualitative and quantitative methods to assess social capital in low income countries. Drawing on two longer and more detailed source documents, we use a six-dimension conceptual framework to show how a more complete picture of the nature and extent of social relations in poor communities can be discerned. Far from being the 'final word' on social capital assessment, these guidelines serve rather to distil lessons from research conducted thus far at the World Bank (and elsewhere), and provide a broad platform on which subsequent research can draw and, in turn, contribute. It is stressed that social capital's salience and manifestations, across all dimensions, is often highly context dependent, and that all researchers need to do the hard work of adapting these guidelines to best suit the political, cultural and historical realities of the communities in which they are engaged.
\end{abstract}

Keywords: social capital, low income, qualitative, quantitative, networks, solidarity, information, communication, cooperation, social cohesion, inclusion

\title{
Acknowledgements
}

This paper provides a brief overview of-while drawing extensively on and seeking to partially integrate-work originally presented in Grootaert et al (2004), which developed a quantitative survey instrument of social capital, and Dudwick et al (2006), which focused on qualitative tools for assessing social capital in context. Those interested in the details of these respective methodological approaches are advised to consult the original source documents. Our indebtedness to our respective colleagues on these projects is duly acknowledged. The views expressed in this paper are those of the authors alone, and should not be attributed to the World Bank or the University of Manchester. 


\section{Introduction}

Social capital, in its best forms, contributes to economic, social and political development by enabling information-sharing, mitigating opportunistic behaviour, and facilitating collective decision-making (Woolcock and Narayan 2000). Although theoretical and conceptual debates properly continue, and will be unlikely to ever reach a clean resolution (Szreter and Woolcock 2004), these have occurred alongside efforts to enhance the quality and scale of empirical data available to assess the claims (and counterclaims) made regarding the efficacy of social capital, especially in the field of international development. The range of data sources now spans the full gamut of social science, from national household surveys, historical records, and field experiments to case studies, key informant interviews and ethnographic investigations; all have been deployed in an effort to better understand the nature and extent of social relations in particular communities, its trajectories over time, and its consequences for human welfare.

Most research conducted on social capital in developing (and, for that matter, developed) countries, however, has been conducted using a single methodological instrument (e.g., surveys or participant observation). With the notable exception of Anirudh Krishna $(2002,2007)$, researchers have worked predominantly with either quantitative or qualitative methods, a consequence being that opportunities for fruitful exchange between approaches have been lost. Moreover, the actual content of the tools used to collect data on social capital-as opposed to the final results obtained from them-have rarely been disclosed or made available to other researchers to draw upon. Seeking to correct this gap, this chapter provides a summary of two instruments (or 'toolkits'), one qualitative and the other quantitative, that have been field-tested by various groups of researchers inside and outside the World Bank.

Far from being the 'final word' on the subject of measurement, the approaches introduced here are more of a 'second word'-that is, an attempt to integrate and build upon select methods used by a 'first generation' of social capital researchers working on various issues in developing countries. The ultimate goal is to work iteratively towards approaches that are increasingly more refined, valid, reliable and useful. As with the conceptual debates discussed above, we have little expectation that a consensus set of 'gold standard' tools will ever emerge; rather, more modestly, our hope is that social capital researchers in diverse contexts will not have to start from scratch each time they begin their work, but will increasingly be able to access effective, field-tested tools and instruments. To this end, and because the salience and manifestations of social capital are so context dependent, researchers working with the materials outlined here are strongly advised to undertake the hard work of judiciously adapting the various component elements to suit the questions and situation at hand; as such, these tools are inherently and perpetually 'work in progress'.

In the sections that follow, we frame the measurement issues around six dimensions of social capital: (1) Groups and networks; (2) Trust and solidarity; (3) Collective action and cooperation; (4) Social cohesion and inclusion; (5) Information and communication; and (6) Empowerment and political action. We present first the qualitative approaches to assessing these six dimensions, and then the quantitative, though ideally both should be incorporated as necessary, whether sequentially or in parallel, given the type of research question being considered. In practice, however, the distinctive skill sets associated with each approach, plus limited time and resources, mean that only one approach tends to be adopted for a specific study. This practice is especially unfortunate in development studies, since the issues under investigation are typically very complex and rarely map neatly or obviously onto a 
single discipline or methodology. To make use of social capital research as part of efforts to improve people's lives, practitioners require a full understanding of how and why local social processes work the way they do.

In order to adequately understand development issues and establish a firm basis on which to draw project and policy recommendations, data that offers both contextspecific "depth" (usually obtained via qualitative methods) and generalisable "breadth" (usually obtained via quantitative methods) is required (Bamberger 2000; Rao and Woolcock 2003). 'Social capital' is one such complex issue that benefits from the coherent integration of qualitative and quantitative approaches. Researchers in the field are thus encouraged to adopt the combination of qualitative and quantitative methods that best correspond to the specific nature of the issues under investigation. There are numerous ways to go about this; one example might be to conduct qualitative focus group discussions to feed into the design of a quantitative survey. Similarly, working with community groups later in the process to map local assets such as public meeting places may help to triangulate and interpret some survey findings. Ideally an iterative process including both qualitative and quantitative methods would be used, but when this is not feasible some infrequent, low-cost use of mixed methods can still add significant value. Given the context- and resourcespecific nature of designing a mixed methods approach, it is difficult, and probably unrealistic, to prescribe such sequencing options in this paper but other references exist to help in the design and implementation phases (e.g., Tashakkori and Teddlie 1998, Rao and Woolcock 2003).

\section{Assessing social capital across six dimensions}

Given the diverse views in the literature about the key features (even the ontological status) of 'social capital', we are only too aware of the equally contentious views regarding whether and how social capital can be measured (and the additional concerns raised by having any such ventures endorsed by the World Bank; see Bebbington et al 2004). Our view is that these differences are best resolved through practice rather than isolated or abstract theoretical debate, and through making increasingly more informed choices about which approaches to use in a given context on the basis of the best information and resources available. The overriding approach we have taken to organising the vast empirical literature is to conceptualise social capital as a household or community-level (i.e., 'micro') variable (as opposed to something that is feature of, say, an entire nation) with six non-exclusive, overlapping dimensions. These dimensions were chosen inductively, largely for convenience and ease of exposition, though they are certainly consistent with the broader empirical literature. Importantly, they are also products of the valuable guidance we received from the two advisory groups ${ }^{1}$ that reviewed the source documents from which this chapter is derived.

We provide here a brief summary of what each dimension covers, and then proceed to explore different approaches to assessing it, first qualitatively and then quantitatively. Schematically, the dimensions reflect the group membership characteristics and subjective perceptions of trust and norms that are most commonly associated with social capital (dimensions 1 and 2), the main ways in

\footnotetext{
${ }^{1}$ These advisory groups comprised members from both inside and outside the World Bank, and included leading scholars as well as development practitioners. The names of the group members are provided (and their valuable contributions duly acknowledged) in the original source documents (i.e., in Grootaert et al 2004 and Dudwick et al 2006).
} 
which social capital operates (dimensions 3 and 4), and the major areas of application or outcomes (dimensions 5 and 6).

Dimension 1: Groups and Networks. The questions here consider the nature and extent of a household member's participation in various types of social organisations, community activities and informal networks, and the range of contributions that one gives and receives from them. It also considers the diversity of a given group's membership, how its leadership is selected, and how one's involvement has changed over time.

Dimension 2: Trust and Solidarity. In addition to the canonical trust question asked in a remarkable number of cross-national surveys over many years, this category seeks to procure data on trust towards neighbours, key service providers, and strangers, and how these perceptions have changed over time.

Dimension 3: Collective Action and Cooperation. This category explores whether and how household members have worked with others in their community on joint projects and/or in response to a crisis. It also considers the consequences of violating community expectations regarding participation.

Dimension 4: Information and Communication. This category of questions explores the ways and means by which poor households receive information regarding market conditions and public services, and the extent of their access to communications infrastructure.

Dimension 5: Social Cohesion and Inclusion. "Communities" are not single entities, but rather are characterised by various forms of division and difference that can lead to conflict. Questions in this category seek to identify the nature and extent of these differences, the mechanisms by which they are managed, and which groups are excluded from key public services. Questions pertaining to everyday forms of social interaction are also considered.

Dimension 6: Empowerment and Political Action. Individuals are "empowered" to the extent they have a measure of control over institutions and processes directly affecting their well-being (World Bank 2002). The questions in this section explore household members' sense of happiness, personal efficacy, and capacity to influence both local events and broader political outcomes.

\section{Using qualitative methods to assess social capital in context}

The case for qualitative research rests on the unique and important insights that it brings in its own right and, secondarily, on its capacity to address the weaknesses of quantitative approaches. Indeed, the respective strengths and weaknesses of qualitative and quantitative approaches are largely complementary-that is, the weaknesses of one approach can be compensated for by the strengths of the other. Qualitative tools can be used to explore issues of process and causality that cannot be inferred from quantitative data alone. Qualitative methods also allow unanticipated responses and issues to arise.

The tools summarised below are most closely associated with the qualitative tradition. While they can be used in their own right, ideally these tools should be part of a broader, integrated methodological strategy for researching social capital. The text that follows is not intended to provide "how-to" guidance on the use of these tools. Rather, it seeks to give the reader a broad understanding of which qualitative tools are relevant to different aspects of social capital research. Additional resources are cited that offer detailed, practical instructions on how to apply these tools.

The first category of qualitative methods can be referred to as participatory approaches (Mikkelsen 1995, Narayan 1995, Robb 2002). Introduced to scholars and practitioners largely through the work of Robert Chambers (see Chambers 1997 and 
Kumar and Chambers 2002), participatory techniques-such as Rapid Rural Appraisal (RRA) and Participatory Poverty Assessments (PPA)-help development agencies learn about local poverty and project impacts in cost-effective ways.

The Rapid Rural Appraisal is especially useful with illiterate respondents (not all of whom are poor), allowing researchers to learn about their lives using simple techniques such as wealth rankings, oral histories, role playing, games, small group discussions, transect walks (see following section), and village map drawings. These techniques permit respondents who are not trained in quantitative reasoning, or who have little education, to provide meaningful graphic representations of their lives in a manner that gives outside researchers a quick snapshot of certain aspects of their living conditions.

RRA can be said to involve instrumental participation through novel techniques that enable researchers to better understand their subjects. A related approach is to use transformative participation techniques, such as Participatory Rural Appraisal (PRA), the goal of which is to facilitate a dialogue (rather than extract information) that assists the poor and others to learn about themselves and thereby gain new insights that lead to social change ("empowerment"). ${ }^{2}$ In PRA exercises, a skilled facilitator helps communities generate tangible visual diagrams of the processes that lead to deprivation or illness, strategies that are used in times of crisis and fluctuation of resource availability and prices across different seasons. Eliciting information in this format helps the poor to conceive of potentially more effective ways to respond to the economic, political, and social challenges in their lives in ways that are not obvious ex ante. The process and findings provide a potentially enduring foundation for community groups to discuss action and change beyond the scope of a specific research agenda.

Participatory methods are conducted in groups. It is essential, therefore, that participants include representatives from each of the major subgroups in a community. The idea is that if a group reaches consensus on a particular issue after some discussion, this consensus will then be representative of views in a given community, be it a village or slum neighbourhood, because outlying views would have been set aside in the process of debate. For this technique to work, the discussion must be extremely well moderated. The moderator must be sufficiently dynamic while also deftly able to steer the discussion in a meaningful direction, to navigate his or her way around potential conflicts and, in the end, establish consensus. The moderator's role is thus key to ensuring that high-quality data is gathered from a group discussion-an inadequate or inexperienced moderator can affect the quality of the data in a manner that is much more acute than an equivalently inadequate interviewer working with a structured quantitative questionnaire. Even with a skilled facilitator, pre-existing relationships between local parties can either enable or undermine productive discussions.

Another important qualitative tool is the key-informant interview, that is, an interview with someone who is a formal or informal community leader or who has a particular perspective relevant to the study, such as women or members of an ethnic minority. Such interviews may be recorded using notes or tape recorder. The researcher may find that it takes some time to establish rapport with the interviewee; some local

\footnotetext{
${ }^{2}$ The Self-Employed Women's Association (SEWA) in India has used a related approach with great success, helping poor slum dwellers to compile basic data on themselves that they can then present to municipal governments for the purpose of obtaining resources to which they are legally entitled. Participatory approaches, however, have the potential for abuse-see Cooke and Kothari (2001) and Brock and McGee (2002).
} 
greeting rituals may also need to be followed. Though some respondents may be intimated by recording technologies, some may find it cathartic to tell their story to someone from outside the community. Expectations and issues such as anonymity must be clearly addressed at the start. Life histories and open-ended personal interviews are additional tools that have long been used in qualitative research. Indeed, it can be illuminating to interview the same people over time, just as it is useful to repeat household surveys.

The qualitative investigator can also engage in varying degrees of "participant observation" as an actual member (e.g., a biography of growing up in a slum), a perceived actual member (e.g., a spy or a police informant in a drug cartel), an invited long-term guest (e.g., an anthropologist), or a more distant and detached short-term observer of a specific community. A final qualitative approach is textual analysis. Historians, archeologists, linguists, and scholars in cultural studies use such techniques to analyze various forms of media, ranging from archived legal documents, newspapers, artifacts, and government records to contemporary photographs, films, music, websites, and television reports. This approach provides interesting insights into local culture and politics untainted by the presence of a researcher.

\section{Applying qualitative tools to the six dimensions of social capital}

Each of the qualitative tools described in the previous section can be used to research the effects of social capital in poor and non-poor communities alike. The subsections that follow provide analytical frameworks-i.e., key questions for focus group discussions and interviews, as well as potentially useful group activities-for each of the six dimensions of social capital outlined in the introduction to this chapter. Because the six dimensions overlap in practice, some questions appear under more than one dimension. By the same token, an inquiry regarding one dimension may shed light on the other dimensions. Naturally, not all questions and issues included in the analytical frameworks that follow will be appropriate in every case. The entries below are therefore not intended as direct questions to respondents, but to better focus the research team on relevant concerns. Effective (and ethical) data collection respects the valuable time of respondents, simplifies the analysis phase, and forces additional rigour on the conceptual design of research. It may also save money.

\section{Dimension 1: Groups and Networks}

Understanding the groups and networks that enable people to access resources and collaborate to achieve shared goals is an important part of the concept of social capital. Informal networks are manifested in spontaneous and unregulated exchanges of information and resources within communities, as well as efforts at cooperation, coordination, and mutual assistance that help maximise the utilisation of available resources. Informal networks can be connected through horizontal and vertical relationships and are shaped by a variety of environmental factors, including the market, kinship, and friendship.

Another kind of network consists of associations, in which members are linked horizontally. Such networks often have clearly delineated structures, roles, and rules that govern how group members cooperate to achieve common goals. These networks also have the potential to nurture self-help, mutual help, solidarity, and cooperative efforts in a community. "Linking" (vertical) social capital, on the other hand, includes relations and interactions between a community and its leaders and extends to wider relations between the village, the government, and the marketplace. 
The questions listed below are intended to get at the nature and extent of peoples' participation in various types of social organisations and networks (formal and informal), and the range of transactions that take place within these networks. The questions also consider the diversity of a given group's membership and how its leadership is selected.

- Focus on several formal and informal groups and summarise their explicit and implicit functions. How often are the groups activated? Are informal groups based on occasions (e.g., weddings, births, or deaths)? What other triggers bring members of a group together?

- What is exchanged (e.g., goods, services, favours, information, goods, moral support, etc.) in community groups or networks?

- What are the most important aims of the exchange (e.g., to meet basic needs, increase income, meet basic social obligations, maintain or expand potentially useful relationships, or some combination thereof)?

- What characteristics are most valued among network members (e.g., trustworthiness, reciprocity, cooperation, honesty, community respect, etc.)?

- Who are the most socially or economically isolated people in the community? How does this isolation correlate with the kind or extent of networks to which these people belong?

- Who plays a leadership or mobilising role in the groups or networks? How are they selected?

\section{Dimension 2: Trust and Solidarity}

This dimension of social capital refers to the extent to which people feel they can rely on relatives, neighbours, colleagues, acquaintances, key service providers, and even strangers, either to assist them or (at least) do them no harm. Adequately defining "trust" in a given social context is a prerequisite for understanding the complexities of human relationships. Sometimes trust is a choice; in other cases, it reflects a necessary dependency based on established contacts or familiar networks. Distinguishing between these two ends of the continuum is important for understanding the range of people's social relationships and the ability of these relationships to endure difficult or rapidly changing circumstances.

- How would you define trust? What are some examples?

- How long have people in a given neighbourhood or community lived together? How well do they know one another?

- Have new groups recently entered the community (e.g., refugees or economic migrants)?

- To what institutions (formal or informal) do people turn when they have individual or family problems?

- On whom do people rely for different kinds of assistance (e.g., goods, labor, cash, finding employment, entering university, etc.)?

- How is trust distributed in the community (e.g., primarily within extended families or clans or through specific networks and/or localities)?

- Do patterns of mistrust and suspicion exist between households or among groups? 


\section{Dimension 3: Collective Action and Cooperation}

Collective action and cooperation are closely related to the dimension of trust and solidarity, however, the former dimension explores in greater depth whether and how people work with others in their community on joint projects and/or in response to a problem or crisis. It also considers the consequences of violating community expectations regarding participation norms. To understand this dimension, interviews with formal and informal community leaders or leaders of NGOs, associations, unions, or other groups (key-respondent interviews) can prove very useful for triangulating data collected in focus group discussions.

- Describe recent examples of collective action that have taken place in the community (or a segment of the community). What was the course and outcome of these activities?

- Who initiated the activities? How were people mobilised?

- Do social, cultural, or legal constraints limit the participation of specific groups (e.g., women, young people, poor people, minorities, etc.)?

- Are some groups, neighbourhoods, and/or households more likely than others to work together, and if so, why?

- Are some groups, neighbourhoods, and/or households more likely to exclude themselves or be excluded from collective activity, and if so, why?

- What kinds of constraints limit peoples' ability or willingness to work together (e.g., lack of time, lack of trust or confidence in outcomes, suspicion toward the mobilisers, etc.)?

- What are the social sanctions for violating expected norms of collective action in the community?

\section{Dimension 4: Information and Communication}

Increasing access to information is frequently recognized as a central mechanism for helping poor communities strengthen their voice in matters that affect their well-being (World Bank 2002). The questions below are intended to explore the ways and means by which households receive and share information regarding such issues as the community at large, market conditions, and public services, as well as the extent of their access to communications infrastructure.

- Inventory the existing communication sources, their actual and perceived reliability, veracity, availability, and the extent to which these sources are used in practice.

- What are the preferred local sources and channels of information?

- What informal sources of information exist in the community? Which members of the community are included or excluded from such sources?

- What information is available through different networks? To different households and/or groups? (i.e., is there differential distribution within the community?)

- What information is not available to different households and/or groups (i.e., what are the limits of differential distribution within the community)?

\section{Dimension 5: Social Cohesion and Inclusion}


Social cohesion and inclusion are closely related to the previous four dimensions of social capital, but focus more specifically on the tenacity of social bonds and their dual potential to include or exclude members of community. Cohesion and inclusion can be demonstrated through community events, such as weddings and funerals, or through activities that increase solidarity, strengthen social cohesion, improve communication, provide learning for coordinated activities, promote civic-mindedness and altruistic behaviour, and develop a sense of collective consciousness.

- Are there recurring disagreements in networks and groups, or even demonstrated conflict?

- What community patterns of differentiation and exclusion exist with respect to opportunities, markets, information, and services?

- What prevents public services and expenditures from reaching the poorest and most vulnerable groups? Are the reasons related to ethnicity, gender, a political agenda, or geographic isolation?

- What are the patterns of inclusion and/or exclusion in political participation?

- How often do people from different social groups intermarry?

- What are the triggers for everyday conflict among members of a network and/or group (e.g., resource competition, serious social cleavages, socioeconomic inequities)?

- What kinds of mediation have taken place to help the community resolve conflicts? Have these worked? Why? For how long?

\section{Dimension 6: Empowerment and Political Action}

Individuals are empowered to the extent that they have a measure of control over the institutions and processes that directly affect their well-being (World Bank 2002). The social capital dimension of empowerment and political action explores the sense of satisfaction, personal efficacy, and capacity of network and group members to influence both local events and broader political outcomes. Empowerment and political action can occur within a small neighbourhood association or at broader local, regional, or national levels. Each level has its own importance and should be considered separately, as well as in conjunction with the others. This dimension also considers social cleavages, whether related to gender, ethnicity, religion, regionalism, or other factors. Key-informant interviews with political and labor leaders, together with representatives of the judicial system and media, are also important for exploring this dimension.

- How do customary, informal laws constrain or facilitate the ability of citizens to exert influence over public institutions?

- How do formal laws constrain or facilitate the ability of citizens to exert influence over public institutions?

- To what extent can members of a community hold public institutions and officials accountable for their actions?

- What kinds of formal and informal mechanisms are available to individuals and groups to demand accountability of local leaders and officials?

- Which groups or segments of the community have the greatest influence over public institutions? 
- What is the source of influence of these groups (e.g., group size, ability to mobilise members or expand member base, connections to power elite, economic importance)?

- Which groups have the least influence over public institutions and why?

\section{Applying quantitative tools to the six dimensions of social capital}

These six dimensions can also be assessed quantitatively, using some form of household survey. ${ }^{3}$ The value of quantitative data is that it can be readily aggregated, allowing for broad generalisations to be drawn over time and space about large numbers of people; as such, they are especially useful for determining the impact of projects and policies. In certain respects, survey data can also be seen as more 'objective', since the household survey format ensures that there is less scope for pressure from other community members to influence how questions are answered.

Examples of questions from each of the six dimensions are included below. Together, these questions constitute the 'core' list of 27 questions identified by the team members and advisory group for the quantitative component of the larger project. A full list of 95 questions is provided in the Social Capital Integrated Questionnaire (SC-IQ) (see Grootaert et al 2004), but given that not all research teams will have the time, resources, or inclination to ask this many questions, the 27 'core' questions represent our best collective effort to reduce the list, if required, to its most essential components.

\section{Dimension 1: Groups and Networks}

Social capital, in its best forms, helps the dissemination of information, reduces opportunistic behaviour, and facilitates collective decision-making. The effectiveness with which social capital, in the form of the associations and networks, fulfills this role depends upon many aspects of these groups, reflecting their structure, their membership, and the way they function. The SC-IQ makes it possible to describe organisations along three key dimensions, namely (i) the density of membership, (ii) the diversity of membership, and (iii) network characteristics.

(i) At the level of households, the density of membership is measured by the average number of memberships of each household in existing organisations (this can be normalised by household size). This basic indicator can be cross-tabulated by location (region, province, urban/rural) or socio-economic characteristics of the household (income group, age and gender of the head of household, religion, ethnic group) to capture the distribution of memberships. The indicator can also be broken down by type of organisation. A functional classification focuses on the prime objective of the association (education, health, credit, etc.). Another useful classification refers to the scope of the group: whether groups operate only in the community, are affiliated with other groups (inside or outside the community), or are part of a federated structure. Groups with linkages often have better access to resources, especially from outside the community, such as from government or NGOs. Using information on memberships, organisations can also be classified as to whether they represent primarily bonding, bridging, or linking social capital (World Bank 2000).

(ii) The SC-IQ data make it possible to assess the internal diversity of membership according to nine criteria: kinship, religion, gender, age,

\footnotetext{
${ }^{3}$ Details on the methodological challenges of measuring social capital via a standard survey instrument are usefully outlined in Fafchamps (2006).
} 
ethnicity/linguistic group, occupation, education, political affiliation, and income level. Diversity information can be used separately or combined in an index. For example, a "diversity score" can be calculated for each organisation, ranging from 0 to 9 . These scores can be averaged over all or weighted to emphasise the most important organisations to which households belong. It is not immediately obvious whether a high degree of internal diversity is a positive or negative factor from the point of view of social capital. One could argue, on the one hand, that an internally homogeneous association would make it easier for members to trust each other, to share information, and to reach decisions. On the other hand, these members may also have similar information so that less would be gained from exchanging information. Furthermore, the coexistence of a series of associations that are each internally homogeneous but along different criteria could render the decision-making process at the community level more difficult. Analysis in several countries has suggested that internally diverse associations yield higher levels of benefits than others, although homogeneous associations make it easier to bring about collective action (Grootaert 1999, 2001).

(iii) Regarding networks, the SC-IQ provides items of information: the size of the network, its internal diversity and the extent to which it would provide assistance in case of need. Because "network" is a difficult concept to define concretely in the context of a household survey, a pragmatic approach has been taken: a network is seen as a circle of "close friends"- that is, people one feels at ease with, can talk to about private matters, or call upon for help. The size of the network then is captured by the number of such close friends. The usefulness of the network is assessed by asking the respondents whether they could turn to the network in a series of hypothetical emergency situations. The answers to these questions can be aggregated to yield a "mutual support score" for the network. Diversity is assessed in a simpler way than was the case for associations, by focusing only on whether the network consists of people with different economic status. This is a key feature to determine the network's ability to provide resources to the respondent in case of need, and thus the network's usefulness in the management of risk.

\section{Sample survey questions}

1. I would like to ask you about the groups or organisations, networks, and associations to which you (or any member of your household) belong. These could be formally organised groups or just groups of people who get together regularly to do an activity or talk about things. Of how many such groups are you or any one in your household a member?

2. Of all these groups to which you or members of your household belong, which one is the most important to your household?

3. Thinking about the members of this group, are most of them of the same....
a. religion
b. gender
c. ethnic or linguistic background/
race/caste/tribe

4. Do members mostly have the same...

a. occupation

b. educational background or level

5. How frequently does this group work with or interact with groups outside the village/neighbourhood?

Never Rarely Occasionally Frequently 
6. About how many close friends do you have these days? These are people you feel at ease with, can talk to about private matters, or call on for help.

7. If you suddenly needed to borrow a small amount of money [RURAL: enough to pay for expenses for your household for one week; URBAN: equal to about one week's wages], are there people beyond your immediate household and close relatives to whom you could turn and who would be willing and able to provide this money?
Definitely
Probably
Unsure
Probably not
Definitely not

\section{Dimension 2: Trust and Solidarity}

Measurement of the more cognitive aspects of social capital in the SC-IQ is organised around the themes of trust and solidarity. Trust is an abstract concept that is difficult to measure in the context of a household questionnaire, in part because it may mean different things to different people. The SC-IQ approach therefore focuses both on generalised trust (the extent to which one trusts people overall) and on the extent of trust in specific types of people. Trust is also viewed in the context of specific transactions, such as lending and borrowing. Because of the difficulties in measuring trust, the questions in this section have a degree of redundancy to them. In part, this serves the purpose of cross-validating the responses to different questions. It is possible to tabulate the answers to each trust question against the usual spatial or socio-economic characteristics, but because of the complexity of the concept of trust, it is recommended to use factor analysis or principal component analysis to identify any underlying common factors across the different questions. This approach has been successfully used in empirical work. For example, a study on trust in Uganda found that from a series of questions on trust, three factors emerged which identified three different dimensions of trust: trust in agencies, trust in members of one's immediate environment and trust in the business community (Narayan and Cassidy 2001).

\section{Sample Survey Questions}

8. Generally speaking, would you say that most people can be trusted or that you can't be too careful in dealing with people?
People can be trusted
You can't be too careful

9. In general, do you agree or disagree with the following statements?

a. Most people in this village/neighbourhood are willing to help if you need it.

b. In this village/neighbourhood, one has to be alert or someone is likely to take advantage of you....

\begin{tabular}{|l|l|l|}
\hline Agree strongly & Agree somewhat & $\begin{array}{l}\text { Neither agree nor } \\
\text { disagree }\end{array}$ \\
\hline Disagree somewhat & Disagree strongly & \\
\hline
\end{tabular}

10. How much do you trust...

a. Local government officials?

b. Central government officials?

\begin{tabular}{|l|l|l|}
\hline To a very great extent & To a great extent & Neither great nor small extent \\
\hline
\end{tabular} 


\begin{tabular}{|l|l|}
\hline To a small extent & To a very small extent \\
\hline
\end{tabular}

11. If a community project does not directly benefit you but has benefits for many others in the village/neighbourhood, would you contribute time or money to the project?

$\begin{array}{llll}\text { Will not contribute } & \text { Will not contribute } & \text { Will contribute } & \text { Will contribute } \\ \text { time } & \text { money } & \text { time } & \text { money }\end{array}$

\section{Dimension 3: Collective Action and Cooperation}

Collective action is the third basic type of proxy indicator for measuring social capital. The usefulness of this indicator stems from the fact that in the vast majority of settings, collective action is possible only if a significant amount of social capital is available in the community. The major exception occurs in totalitarian societies where the government can force people to work together on infrastructure projects or other types of common activities. Thus, the validity of the collective action indicator as a measure of social capital needs to be evaluated against the political context of a society. The indicators of structural and cognitive social capital discussed previously can be helpful here. Collective action is an important aspect of community life in many countries, although the purposes of the action may differ widely. In some countries, collective action consists primarily of community-organised activities for building and maintaining infrastructure and for providing related public services. In other countries, collective action is more politically oriented and used primarily to lobby elected officials to provide more services to the community.

The collective action section of the SC-IQ aims to collect: the extent of collective action, the type of the activities undertaken collectively, and an overall assessment of the extent of willingness to cooperate and participate in collective action. Each of these variables can be cross-tabulated against the usual set of spatial and socio-economic variables to obtain a pattern of the incidence of collective action. More interestingly perhaps is the cross-tabulation of collective action variables against the indicators of structural and cognitive social capital discussed previously. This would reveal whether communities with a high density of organisations and/or high levels of trust also display higher levels of collective action. Any correlations revealed by such tabulations could usefully be the subject of further multivariate analysis.

\section{Sample Survey Questions}

12. In the past 12 months did you or anyone in your household participate in any communal activities, in which people came together to do some work for the benefit of the community?

\begin{tabular}{|l|l|}
\hline Yes & No (skip to question 14) \\
\hline
\end{tabular}

13. How many times in the past 12 months?

14. If there was a water supply problem in this community, how likely is it that people will cooperate to try to solve the problem?

Very likely Somewhat likely $\begin{array}{ll}\text { Neither likely } \\ \text { nor unlikely }\end{array} \quad \begin{aligned} & \text { Somewhat } \\ & \text { unlikely }\end{aligned} \quad$ Very unlikely


Module 4 of the SC-IQ has a simple structure: it is a list of sources of information and means of communication. Analysis of this information is equally straightforward. Each item can be cross-tabulated separately against spatial and socio-economic variables to identify whether certain areas or groups have better, or worse, access to information and communication. The identified pattern can be compared against the pattern of structural and cognitive social capital established on the basis of the previous modules. If areas of low social capital are found to have poor access to information and communication, a further inquiry into possible causality might be warranted.

The information from module 4 can also be aggregated, either at the household level or at the community level, to obtain a single score for information and communication access. Factor analysis or principal component analysis are suitable techniques to that effect. Additional questions enable an assessment of the relative importance of groups and networks as sources for important information compared to "impersonal" sources such as newspapers or television. Information on government activities and markets is directly relevant for the generation of income and/or for non-monetary aspects of wellbeing, and can therefore be included as an explanatory variable in multivariate analysis of household well-being.

\section{Sample Survey Questions}

15. In the past month, how many times have you made or received a phone call?

16. What are your three main sources of information about what the government is doing (such as agricultural extension, workfare, family planning, etc.)?

\begin{tabular}{|c|c|c|c|}
\hline Relatives & $\begin{array}{l}\text { Friends and } \\
\text { neighbours }\end{array}$ & $\begin{array}{l}\text { Community } \\
\text { bulletin board }\end{array}$ & Local market \\
\hline $\begin{array}{l}\text { Community or } \\
\text { local newspaper }\end{array}$ & $\begin{array}{l}\text { National } \\
\text { newspaper }\end{array}$ & Radio & Television \\
\hline $\begin{array}{l}\text { Groups or } \\
\text { associations }\end{array}$ & $\begin{array}{l}\text { Business or work } \\
\text { associates }\end{array}$ & $\begin{array}{l}\text { Political } \\
\text { associates }\end{array}$ & Community leader \\
\hline $\begin{array}{l}\text { An agent of the } \\
\text { government }\end{array}$ & NGOS & Internet & \\
\hline
\end{tabular}

\section{Dimension 5: Social Cohesion and Inclusion}

Module 5 of the SC-IQ brings together three related topics: inclusion, sociability, and conflict and violence. The section on inclusion ranges from general perceptions of social unity and togetherness of the community to specific experiences with exclusion. The respondent is first asked whether there are any divisions in the community and, if so, what characteristics cause it. Questions on exclusion from services at the level of the community are followed by more direct questions, such as whether the respondent has ever been the victim of exclusion. The most policy-relevant information will come from the detailed cross-tabulation of the presence of exclusion by type of service against the characteristics deemed to be the grounds for exclusion. This tabulation will reveal whether exclusion exists across the board, due to characteristics such as gender or ethnicity, or if the reasons for exclusion vary by type of service or activity. Such information has a high diagnostic value in identifying sources of social stress in the community. To compare the incidence of exclusion across communities, an "exclusion score" can be constructed by adding up the answers from several questions. 
One of the positive manifestations of a high level of social capital in the community is the occurrence of frequent every-day social interactions. This "sociability" can take the form of meetings with people in public places, visits to other people's homes or visits from others into one's own home, and participation in community events such as sports or ceremonies. The section on sociability in module 5 covers each of these situations. In order to distinguish whether these daily social interactions are of the bonding or bridging variety, questions are asked whether the people with whom one meets are of the same or a different ethnic or linguistic group, economic status, social status, or religious group. The diversity of social interactions can usefully be compared to the diversity of the membership of associations (covered in module 1). Put together, these two items of information on diversity give a good picture of the internal divisiveness or cohesiveness of a community and whether bonding or bridging social capital predominates.

The presence of conflict in a community or in a larger area is often an indicator of the lack of trust or the lack of appropriate structural social capital to resolve conflicts, or both. The SC-IQ brings together three important items of information on conflict and violence: the extent and trend of violence, the contribution made by internal divisiveness in the community, and the feelings of insecurity stemming from fear of crime and violence. To match perceptions with fact, certain questions in this module ask about the household's recent experience of crime. It is useful to tabulate this information both at the household level and the community level. It is quite likely that perceptions of violence as well as experience of it differ between rich and poor households, old and young people, etc. Likewise, different communities can have vastly different experiences with conflict and violence, even if they are geographically close. The comparison of communities will be made easier if the different questions on conflict and violence in module 5 are aggregated, either directly or by means of factor analysis.

\section{Sample Survey Questions}

17. There are often differences in characteristics between people living in the same village/neighbourhood. For example, differences in wealth, income, social status, ethnic or linguistic background/race/caste/tribe. There can also be differences in religious or political beliefs, or there can be differences due to age or sex.

To what extent do any such differences characterise your village/neighbourhood? Use a five point scale where 1 means to a very great extent and 5 means to a very small extent.

\section{Do any of these differences cause problems?}

\section{Yes} No (go to question 21)

19. Which two differences most often cause problems?

Differences: in education; in landholding; in wealth/material possessions; in social status; between men and women; between younger and older generations; between long-term and recent residents; in political party affiliations; in religious beliefs; in ethnic or linguistic background/race/caste/tribe? Other differences?

20. Have these problems ever led to violence?

Yes No

21. How many times in the past month have you got together with people to have food or drinks, either in their home or in a public place? 
22. [IF NOT ZERO] Were any of these people of different...

\begin{tabular}{|l|l|}
\hline Ethnic or linguistic background/race/caste/tribe? & Economic status? \\
\hline Social status? & Religious groups? \\
\hline
\end{tabular}

23. In general, how safe from crime and violence do you feel when you are alone at home?

\begin{tabular}{|l|l|l|l|l|}
\hline Very safe & $\begin{array}{l}\text { Moderately } \\
\text { safe }\end{array}$ & $\begin{array}{l}\text { Neither safe } \\
\text { nor unsafe }\end{array}$ & $\begin{array}{l}\text { Moderately } \\
\text { unsafe }\end{array}$ & Very unsafe \\
\hline
\end{tabular}

\section{Dimension 6: Empowerment and Political Action}

The final section of the SC-IQ takes a broad view that transcends social capital. Empowerment refers to the expansion of assets and capabilities of people to participate in, negotiate with, influence, control, and hold accountable, institutions that affect their lives (World Bank 2002). Empowerment is brought about by a wide range of actions, such as making state institutions more responsive to poor people, removing social barriers, and building social opportunity (World Bank 2000). Empowerment is thus a broader concept than social capital, and political action is only one of many activities that can be undertaken to increase empowerment.

In the context of the SC-IQ, empowerment is defined more narrowly as the ability to make decisions that affect everyday activities and may change the course of one's life. Respondents are asked to assess this ability directly. As discussed above, political action is one venue to practice and possibly increase this ability. Module 6 considers a number of concrete political activities such as filing petitions, attending public meetings, interacting with politicians, participating in demonstrations and campaigns, and voting in elections. The analysis of this information can follow a pattern similar to that recommended for the previous module. The data can be aggregated both at the level of the household and the level of the community. Different households, depending upon their demographic, economic and social characteristics, will feel differently empowered and will participate in political action to differing degrees. It is useful to compare this pattern of empowerment with the patterns of access to information, fear of violence, sociability, and other dimensions of social capital derived from other modules. By the same token, earlier analysis will already have provided a community score of social cohesiveness and inclusion, and this information can usefully be complemented with a community score of empowerment and political action.

\section{Sample Survey Questions}

24. In general, how happy do you consider yourself to be?

\begin{tabular}{|l|l|l|l|l|}
\hline Very happy & $\begin{array}{l}\text { Moderately } \\
\text { happy }\end{array}$ & $\begin{array}{l}\text { Neither happy } \\
\text { nor unhappy }\end{array}$ & $\begin{array}{l}\text { Moderately } \\
\text { unhappy }\end{array}$ & Very unhappy \\
\hline
\end{tabular}

25. Do you feel that you have the power to make important decisions that change the course of your life? Rate yourself on a 1 to 5 scale, where 1 means being totally unable to change your life, and 5 means having full control over your life.

26. In the past 12 months, how often have people in this village/neighbourhood got together to jointly petition government officials or political leaders for something benefiting the community? 


\begin{tabular}{|l|l|l|l|}
\hline Never & Once & A few times $(<5)$ & Many times $(>5)$ \\
\hline
\end{tabular}

27. Lots of people find it difficult to get out and vote. Did you vote on the last state/national/ presidential election?

Yes

No

\section{Conclusion: integrating qualitative and quantitative approaches to assessing social capital}

Increasing evidence shows that social cohesion is critical for societies to prosper economically and for development to be sustainable. Social capital is not just the sum of the institutions which underpin a society; it is the glue that holds them together. Social capital is multi-dimensional in nature. Given that it is most frequently defined in terms of groups, networks, norms of reciprocity, cooperation, and trust, research on social capital must be able to capture this multi-dimensionality. In order to make use of social capital findings to improve development processes and outcomes, it is also necessary to understand the dynamic nature of interpersonal and group relations in the context in which it is being studied. As such, social capital readily lends itself to a mixed-methods research approach. Employing both qualitative and quantitative methods allows researchers to uncover the links between different dimensions of social capital and poverty, as well as to construct a more comprehensive picture of the structures, perceptions and processes of social capital in a given locality.

Even if quantitative and qualitative approaches are construed as existing along a continuum (Bamberger 2000), rather than being wholly distinctive, the fact remains that most individual researchers are trained in and hired to perform primarily only one approach. The organisational imperatives of large development agencies also tend to give higher priority to quantitative approaches, which provide the 'de-contextualised' (though putatively 'more objective') measures that enable such agencies to "see" complex problems and diverse contexts in ways that comport with their particular capacity to respond to them (Scott 1998). Using and/or integrating both methods requires a deliberate choice and sustained commitment on the part of a research team; informing and facilitating such choices is one of the primary goals of this chapter (and the broader project from which it draws).

Many researchers have stressed the limitations of different approaches and/or called for more methodological pluralism in development research. Indeed, starting with the work of Epstein (1962), many researchers have made important contributions to development research by working across methodological lines (Tashakkori and Teddlie 1998, Bamberger 2000, Gacitua-Mario and Wodon 2001). Ideally, researchers should endeavor to understand the strengths and weaknesses of each approach and discern practical strategies for combining them on a more regular basis when assessing social capital (Kanbur 2003, Rao 2002). ${ }^{4}$ It is important to note, however, that because qualitative research enables discussion on processes and, implicitly or explicitly, power relations, it carries the risk of aggravating local conflict. Well-intentioned researchers bear responsibility for that risk. In fact, both methodological approaches can unearth delicate relationship issues and raise local expectations; therefore careful planning, management and follow-through are essential to do no harm. At a minimum, researchers should plan to disseminate their

\footnotetext{
${ }^{4}$ King, Keohane, and Verba (1994) and Brady and Collier (2004) provide more academic treatments of the potential commonalities of quantitative and qualitative approaches.
} 
findings to local stakeholders at various stages of the exploration and ideally would consider how local follow up can be integrated into on-going government, civil, or private initiatives.

In summary, combining qualitative and quantitative approaches to the assessment of social capital offers practitioners several advantages. First, they gain a clearer, more nuanced understanding of the context of the communities and/or regions for which they design, monitor, and evaluate development interventions. Second, the two methods in combination can provide baseline socio-economic information that can improve the design of both research tools (e.g., a living standards survey or poverty assessment survey) and development projects. Third, quantitative and qualitative research methods together yield better impact and evaluation data, enabling teams to understand the full impact of projects on social capital (which can be positive, negative, or both), and conversely, whether areas with certain types and levels of social capital experience more successful project implementation than areas with other types and levels of social capital. Finally, when analysed and disseminated locally, integrated quantitative and qualitative findings can be sources of empowerment, enabling better understanding of the present and potentially new visions of the future. In this spirit, the present chapter will have served its purpose if it helps realise such goals; indeed, it is precisely through such pragmatic processes that the otherwise more abstract conceptual and methodological debates that continue to surround the idea of social capital should be (more than marginally) informed. 


\section{References}

Bamberger, Michael (2000) Integrating Quantitative and Qualitative Research in Development Projects Washington, DC: World Bank.

Bebbington, Anthony, Scott Guggenheim, Elizabeth Olson and Michael Woolcock (2004) "Exploring Social Capital Debates at the World Bank" Journal of Development Studies 40(5): 33-64

Brady, Henry and David Collier (eds.) (2004) Rethinking Social Inquiry: Diverse Tools, Shared Standards Lanham, MD: Rowman and Littlefield

Brock, Karen, and Rosemary McGee (2002) Knowing Poverty: Critical Reflections on Participatory Research and Policy London: Earthscan Publications

Chambers, Robert (1997) Whose Reality Counts? Putting the First Last London: Intermediate Technology Publications

Cooke, Bill and Uma Kothari (2001) Participation: The New Tyranny? London: Zed Books

Dudwick, Nora, Kathleen Kuehnast, Veronica Nyhan Jones and Michael Woolcock (2006) "Analyzing Social Capital in Context: A Guide to Using Qualitative Methods and Data" World Bank Institute Working Paper No. 37260. Washington, DC: The World Bank

Epstein, Scarlet (1962) Economic Development and Social Change in South India. Manchester, UK: University of Manchester Press

Estrella, Marisol, and John Gaventa (1998) "Who Counts Reality? Participatory Monitoring and Evaluation: A Literature Review" IDS Working paper No. 70, Institute of Development Studies, University of Sussex, Brighton, United Kingdom

Fafchamps, Marcel (2006) "Development and Social Capital" Journal of Development Studies 42(7): 1180-98

Gacitua-Mario, Estanislao and Quinton Wodon (eds.) (2001) "Measurement and Meaning: Combining Quantitative and Qualitative Methods for the Analysis of Poverty and Social Exclusion in Latin America" Technical Paper 518, Latin America and Caribbean Region, World Bank, Washington, DC

Grootaert, Christiaan (1999) "Social Capital, Household Welfare, and Poverty in Indonesia" Policy Research Working Paper 2148. Washington D.C.: World Bank.

Grootaert, Christiaan (2001) "Does Social Capital Help the Poor? A Synthesis of Findings from the Local Level Institutions Studies in Bolivia, Burkina Faso, and Indonesia." Local Level Institutions Working Paper 10. World Bank, Social Development Department, Washington DC

Grootaert, Christiaan, Deepa Narayan, Veronica Nyhan Jones and Michael Woolcock (2004) "Measuring Social Capital: An Integrated Questionnaire" World Bank Working Paper No. 18. Washington, DC: The World Bank 
Hentschel, Jesko (1999) "Contextuality and Data Collection Methods: A Framework and Application for Health Service Utilization" The Journal of Development Studies 35(4): 64-94

Kanbur, Ravi (2003) Q Squared: Qualitative and Quantitative Methods of Poverty Appraisal New Delhi: Permanent Black

King, Gary, Robert Keohane, and Sidney Verba (1994) Designing Social Inquiry: Scientific Inference in Qualitative Research Princeton, NJ: Princeton University Press

Krishna, Anirudh (2002) Active Social Capital: Tracing the Roots of Development and Democracy. New York: Columbia University

Krishna, Anirudh (2007) "How Does Social Capital Grow? A Seven-Year Study of Villages in India" Journal of Politics 69(4): 941-956

Krishna, Anirudh, and Elizabeth Shrader (2000) "Cross-sectoral measures of social capital: A tool and results from India and Panama" Social Capital Initiative Working Paper No. 21. Social Development Department, World Bank, Washington, DC

Kumar, Somesh, and Robert Chambers (2002) Methods for Community Participation London: Intermediate Technology Publications

Mikkelsen, Britha (1995) Methods for Development Work and Research: A Guide for Practitioners New Delhi: Sage Publications

Narayan, Deepa (1995) Toward Participatory Research. Washington, DC: The World Bank

Narayan, Deepa, and Michael Cassidy (2001) "A Dimensional Approach to Measuring Social Capital: Development and Validation of Social Capital Inventory" Current Sociology 49(2): 49-93

Rao, Vijayendra (2002) "Experiments in 'Participatory Econometrics': Improving the Connection between Economic Analysis and the Real World" Economic and Political Weekly (May 18): 1887-91

Rao, Vijayendra and Michael Woolcock (2003) "Integrating Qualitative and Quantitative Approaches in Program Evaluation", in Francois J. Bourguignon and Luiz Pereira da Silva (eds.) The Impact of Economic Policies on Poverty and Income Distribution: Evaluation Techniques and Tools New York: Oxford University Press, pp. $165-90$

Robb, Carolyn (2002) Can the Poor Influence Policy? Participatory Poverty Assessments in the Developing World (Rev. ed.) Washington, D.C.: International Monetary Fund

Scott, James (1998) Seeing Like a State: How Well-Intentioned Schemes to Improve the Human Condition Have Failed New Haven: Yale University Press

Szreter, Simon and Michael Woolcock (2004) "Health by Association? Social Capital, Social Theory and the Political Economy of Public Health" International Journal of Epidemiology 33(4): 650-67 
Tashakkori, Abbas, and Charles Teddlie (1998) Mixed Methodology: Combining Qualitative and Quantitative Approaches Thousand Oaks, CA: Sage

Woolcock, Michael and Deepa Narayan (2000) "Social Capital: Implications for Development Theory, Research, and Policy" World Bank Research Observer 15(2): 225-50

World Bank (2000) World Development Report 2000/2001: Attacking Poverty. New York: Oxford University Press

World Bank (2002) Empowerment and Poverty Reduction-A Sourcebook Washington D.C.: World Bank 
Executive Director

Professor Tony Addison

Research Director

Professor Michael Woolcock

Associate Director

Professor David Hulme

\section{Contact:}

Brooks World Poverty Institute

The University of Manchester

Humanities Bridgeford Street

Building

Oxford Road

Manchester

M13 9PL

United Kingdom

\section{Email: bwpi@manchester.ac.uk}

The Brooks World Poverty Institute (BWPI) creates and shares knowledge to help end global poverty.

BWPI is multidisciplinary, researching poverty in both the rich and poor worlds.

Our aim is to better understand why people are poor, what keeps them trapped in poverty and how they can be helped - drawing upon the very best international practice in research and policy making.

The Brooks World Poverty Institute is chaired by Nobel Laureate, Professor Joseph E. Stiglitz. 